\title{
Amniotic Fluid Embolism (AFE): A Review of the Literature Orientated on Two Clinical Presentations- Typical and Atypical
}

\author{
Waldemar Uszyński ${ }^{1}$, Mieczysław Uszyński ${ }^{2 *}$ \\ ${ }^{1}$ Regional Hospital, Włocławek, Poland \\ ${ }^{2}$ Department of Propedeutics of Medicine, Collegium Medicum in Bydgoszcz, Nicolaus Copernicus University, Toruń, Poland \\ Email: "kizproped@amb.bydgoszcz.pl
}

Received 4 December 2013; revised 28 December 2013; accepted 4 January 2014

Copyright (C) 2014 Waldemar Uszyński, Mieczysław Uszyński. This is an open access article distributed under the Creative Commons Attribution License, which permits unrestricted use, distribution, and reproduction in any medium, provided the original work is properly cited. In accordance of the Creative Commons Attribution License all Copyrights (C 2014 are reserved for SCIRP and the owner of the intellectual property Waldemar Uszyński, Mieczysław Uszyński. All Copyright (c) 2014 are guarded by law and by SCIRP as a guardian.

\section{ABSTRACT}

Background/Aim: Recently, a comparative study on the incidence of AFE has highlighted rather confusing results, showing that the complication is more than three times higher in North America than that in some European countries. In this paper, we put forward the hypothesis that this discrepancy is due to inaccurate diagnosis of non-classical form of AFE (atypical AFE). We also provide an outline of symptoms that characterize this type of AFE based on the analysis of all available case reports. Material and Methods: We searched Medline from 1969 (its inception) to 2011, using the key words "amniotic fluid embolism". The search produced 1127 articles, including 208 case reports of AFE and other publications identified as eligible for our study (11 review articles and 6 population-based studies of the last few years). Moreover, we looked through the articles from the period before "inception of Medline" to find 178 earlier case reports. Full texts were analyzed. Results and Conclusions: (i) Worldwide, 447 cases of AFE have been reported, including 70 cases of atypical AFE (15.7\%). (ii) Typical AFE is characterized by three clinical phases (cardiopulmonary collapse, clotting disorders and hemorrhages, multiorgan disturbances), whereas the atypical one shows lack of cardiopulmonary collapse as the initial presentation-the first to appear is obstetric hemorrhage and/or pulmonary and renal dysfunction. (iii) Four subclasses of atypical AFE were distinguished on the basis of case reports: uterine hemorrhage-type of AFE, ARDS as the only presentation of

*Corresponding author. atypical AFE, paradoxical AFE, and cesarean sectionrelated atypical AFEs.

\section{KEYWORDS}

Amniotic Fluid Embolism; Mother Mortality; Classification; Presentation

\section{INTRODUCTION}

Amniotic fluid embolism (AFE) (Latin: embolia liquore amniotico) is a rare, yet an extremely dangerous perinatal complication, caused by invasion of the amniotic fluid to the maternal circulation. This leads to life threatening complications, for both mother and child, such as cardiopulmonary collapse, often with cardiac arrest, hemorrhage with coagulopathy and multiorgan failure (adoult respiratory distress syndrome, ARDS, and others) in mother, and effects of severe asphyxia in child. AFE takes place during or after labor (70\% and $11 \%$, respectively) and cesarean section (19\%) [1]. Moreover, amniotic fluid embolism-like syndrome has been reported to follow artificial abortion, transabdominal amniocentesis, manual removal of placenta, placenta percreta and others.

AFE was first described in 1926 by Meyer, a Brazilian gynecologist [2], who detected morphotic elements of the amniotic fluid in the lungs of a dead parturient; however, his observation remained unnoticed at that time. Another description came from 1941, when Steiner and Lusbaugh, American gynecologists [3], reported the findings of their pathomorphological investigations of the lung tissue in eight parturient women who had died suddenly; in the pulmonary arterioles, the researchers identified morphological and amorphic components of the amniotic 
fluid (fetal squames, lanugo, mucus streaks, lipid droplets). Since then, the above profile started to be considered the major symptoms though not pathognomonic evidence for AFE. Currently, the diagnosis of AFE is based on the clinical picture of the complication and differential diagnostics, whereas pathomorphological and laboratory investigations are reckoned as accessory to the clinical diagnosis.

The pathomechanism of AFE was explained based on three known theories and the unified concept of AFE has been published recently [4,5]. However, AFE still remains medical enigma, since many issues are unexplained. It is still unclear why AFE, which is usually typical, having three clinical phases with cardiopulmonary collapse as initial presentation, can also have an atypical course (initial presentation can be the disseminated intravascular coagulation-DIC-with or without hemorrhage as well as only isolated DIC or/and Acute Respiratory Distress Syndrome, ARDS).

Recently, the comparative study on the incidence of AFE has highlighted rather confusing results revealing that the complication is over three times more common in North America than that in some European countries $[6,7]$. However, it is not clear whether all clinicians follow the same criteria to build up the diagnosis. The discrepancy in the results may be caused by the non-classical presentation of AFE. In the current paper, we tried to consider the diagnostic aspects of literature data regarding the two forms of AFE, i.e. typical and atypical ones.

\section{STUDY OBJECTIVE}

We put forward the hypothesis that the discrepancies in the assessment of AFE incidence rate are due to inaccurate diagnosis of atypical AFE. We wanted to find out how often atypical AFE is diagnosed and what symptoms are associated with this complication.

At first, we identified all available reports concerning AFE published in English, German, French, Polish and Russian starting from the first two publications [2,3] until 2011; papers from the period "before inception of Medline” were obtained from our private collections and the Polish Library Base.

Next, we summed up the number of the reported cases of typical and atypical AFE, and distinguished four subgroups of this latter complication.

\section{MORBIDITY AND MORTALITY RATE}

In developed countries, AFE is the cause of $5 \%-15 \%$ of all deaths of mothers, being the main cause in Australia, the second in the USA and the third in France and Poland [7-9]. In Poland, in the years 1991-2000, forty-seven parturient patients died of AFE, which accounted for nearly $10 \%$ of all maternal deaths [9]. A direct cause of death was cardiac arrest (most common cause), obstetric hemorrhage with clotting disorders (the second most common) and pulmonary complications.

According to earlier publications, the incidence of AFE was found to range from 1:8000 to $1: 80,000$ labors, with a $60 \%$ mortality rate among mothers (range $13 \%$ - $86 \%$, literature survey: [7]). However, the data obtained in the last decades are much better, e.g. the incidence of AFE in North America is estimated at 1:15,200 labors, and in Europe over three times lower (1:53,800 labors [7]). These discrepancies have evoked a suspicion that in the USA and Canada AFE was overestimated.

Nowadays, epidemiological data concerning AFE are expressed in terms of incidence rate and mortality rate, which accounts for the number of morbidity cases or deaths of mothers per 100,000 live births or deliveries, respectively. The reported incidence ranged from 1.9 cases per 100,000 maternities in the United Kingdom, through the Netherlands, the USA and Canada to 6.1 per 100,000 maternities in Australia [7].

\section{NUMBER OF REPORTED CASES OF AFE WORLDWIDE}

By 2011, 447 cases of AFE were reported worldwide, including 70 cases of atypical AFE (15.7\%). In the group of 70 cases of atypical AFE, we found 34 identified earlier by Morgan, 12 cases reported by Clark et al. in 1995 [1], and 24 cases in the literature published in the years 1995-2011 (Table 1). To the best of our knowledge this is the first attempt to calculate all published cases of AFE in the world.

\section{RISK FACTORS}

Risk factors of AFE are regularly the object of epidemiological studies [6-8]. A strong statistical correlation has been found between AFE and a few potential risk factors [7]: a/age above 35 years - the risk increases with age and there is a growing trend in maternal age; b/cesarean delivery - there is a rising trend in cesarean delivery rates - the higher the frequency of cesarean section delivery the more increased the risk for AFE; c/placental complications, mainly such as abruptio placentae and placenta previa.

Table 1. Total number of cases of amniotic fluid embolism described worldwide.

\begin{tabular}{ccc}
\hline Period & $\begin{array}{c}\text { Total number of } \\
\text { reported AFE cases }\end{array}$ & Atypical AFE \\
\hline $\begin{array}{c}\text { 1926-1969 (period before } \\
\text { Medline Inception) }\end{array}$ & 178 & \\
$\begin{array}{c}\text { Medline as the source of } \\
\text { information (1969-2011) }\end{array}$ & 269 & 70 \\
Total & $447(100 \%)$ & $70(15.7 \%)$ \\
\hline
\end{tabular}


For many decades, scientists have discussed whether AFE can be a side effect of oxytocin administration. In 2012, Kramer et al. [10] analyzed 120 fatal cases of AFE and found out that medical induction of labor was the strongest among the risk factors (medical induction, caesarean delivery, instrumental vaginal delivery, and uterine or cervical trauma).

\section{TYPICAL PRESENTATION OF AFE}

In the past, the diagnosis of AFE was based on dispersed knowledge, i.e. on the symptoms recorded in case reports. It was only in 1964 that Albrechtsen [11] summarized individual reports, outlining a three-phase clinical picture of AFE, later defined as typical. In 1995 Clark et al. [1] formulated diagnostic criteria of typical AFE, now referred to as classical.

Phase 1 (cardiopulmonary collapse): Prodromal symptoms most probably precede each embolic event, although they are not always mentioned in the descriptions. Patients experience pricking sensation in the chest, chills, dry cough, anxiety, tetanic uterine contractions and fetal distress (late decelerations and meconium-stained amniotic fluid). The first symptoms, besides the prodromal ones, include dramatic respiratory and circulatory disorders-breathing becomes fast, shallow and irregular (dyspnoe, tachypnoe), cyanosis appears, changing quickly into pallor, blood pressure drops rapidly, pulse becomes fast and thready; many patients lose consciousness and cardiac arrest is frequently noted. In the past, the above disorders were called obstetric shock, whereas nowadays they are referred to as obstetric nonhemorrhagic and noncardiogenic shock [12].

To date, researchers have failed to perform hemodynamic investigations within the first 60 minutes of an embolic event in humans; hence the observations made in animals cannot be confronted with (potential) clinical findings. The experimental model demonstrates the predominance of right ventricular failure [13]; however, this may differ in humans. Clark [14] has assumed that hemodynamic disturbances in human subjects have a twophase course: (a) initially, symptoms of right ventricular failure are observed (pulmonary artery hypertension, increased blood pressure in large veins); (b) later, left ventricular failure develops, especially left atrial failure with pulmonary hypertension which is referred to as secondary hypertension (due to left atrial or/and ventricular failure).

Approximately 10 years ago transesophageal echocardiography was first applied in AFE [15,16], confirming that cardiac dysfunction and coagulation disorders (disseminated intravascular coagulation-DIC) begin in the early phase of embolism, are simultaneous and that intracardiac thrombi play a destructive role. One of the procedures was performed in minute 10 of a respiratory-cir- culatory collapse [16] to find, among others, right ventricular dilation with prominent interventricular septum due to blood overwhelming, left ventricular reduction (lack of blood supply implicating pulmonary blood flow obstruction), and atrial dysfunction. Another case [17] described transient thrombi in the right ventricle, which disappeared after heparin administration.

Phase 2 (coagulation and hemostatic disorders): Most patients who have survived phase 1 develop coagulation disorders (ca. 50\%) [1] and life threatening hemorrhages (uterine hemorrhage, wound bleeding). Uterine atony is common, but not always (cases of uterine hemorrhage have been described, with well-contracted uterine and flowing blood that neither coagulated nor contained clots).

Coagulation disorders in AFE are called consumption coagulopathy, as the consumption of coagulation factors occurs in the process of disseminated intravascular coagulation (DIC). Clinical tests of coagulation in AFE show low platelet counts and decreased level of coagulation factors, mainly fibrinogen, which results from the exhaustion of these components in the coagulation process; on the other hand, they reveal high levels of D-dimers (products of thrombin-plasmin changes in fibrinogen indicating active coagulation processes and secondary fibrinolysis).

The knowledge of the mechanism of coagulation disorders in AFE is based on laboratory tests performed an hour after the onset of symptoms, since to date no blood samples have been collected immediately afterwards. Therefore, the assumption that the coagulation process develops already at the beginning of the embolic event, being on the verge of certainty, requires some unquestionable evidence, such as the levels of thrombin markers in maternal blood (prothrombin F $1+2$ fragments, thrombin antithrombin complex, TAT and fibrinopeptides A).

High fibrinolytic activity at the onset of AFE has been noticed by a few authors. In 1977, Graeff et al. [18] monitored a few parameters of fibrinolysis, starting from minute 15 of an embolic event. At that time, nearly the whole plasma fibrinogen pool underwent thrombin-plasmin transformations; fibrinogen concentration was only $15 \mathrm{mg} \%$, and the levels of early and late products of fibrinogen degradation were estimated to be very high. The authors were convinced that AFE caused rapid DIC at first and reactive hyperfibrinolysis as the secondary process. Nowadays, the activity of the coagulation-fibrinolysis processes is assessed based on the level of D-dimers.

Phase 3 (multiorgan dysfunction) and distant complications: Organ disorders may develop a few hours after the onset of symptoms or later, including ARDS (Acute Respiratory Distress Syndrome) and/or kidney dysfunction. ARDS is known as a noninfectious inflammatory process of small bronchi accompanied by exudate to the 
lumen of the pulmonary alveoli; the originating hyaline membranes interfere with gas exchange. Renal dysfunction, previously called the lower nephron syndrome, is kidney reaction to hypovolemia; reduced diuresis is the first signal of renal dysfunction.

Distant complications may appear both in mother and child. These are usually neurological abnormalities, but also abortive Sheehan's syndrome and adrenal cortex dysfunction have been reported in the mother. Neurologically intact survival women were seen in $15 \%$ and only $50 \%$ of survival infants were neurologically normal [1]. More recent study by Tuffnell [19] has provided less pessimistic results.

\section{SINCE WHEN HAS THE DIAGNOSIS OF "ATYPICAL AFE" BEEN MADE?}

Non-classical, atypical AFE was first described in 1969 by Morgan [20]. The author performed meta-analysis of 272 AFE cases and found out that 34 of them (12.8\%) were atypical with hemorrhage in the peripartum period, and not catastrophic cardiopulmonary collapse as the initial presentation. In 1995, Clark et al. [1] in a group of 69 cases identified 12 (17.4\%) with an uncommon AFE variant involving isolated disseminated intravascular coagulation (DIC) that developed without antecedent cardiopulmonary disturbances. Later, similar observations were made by other authors, confirming that the first symptom could be isolated DIC with or without postpartal hemorrhage [21,22]. In 1992, Masson [23] presented a well-documented case in which the only presentation of AFE was pulmonary complication (ARDS) and disseminated intravascular coagulation without bleeding. A similar case was reported in Poland in the year 2003 [24].

In the years 1998-2004, such terms as "atypical presentation of amniotic fluid embolism”, “amniotic fluid embolism and isolated disseminated intravascular coagulation", "amniotic fluid embolism with isolated coagulopathy..." and "transient intracardiac thrombi in amniotic fluid embolism" appeared in report headlines. Symptoms described in these reports [17,21,22,25-27], as well as in others [28-38], were the basis for distinguishing four subclasses of atypical AFE (Figure 1). Interestingly, in a few cases of atypical AFE circulating epithelial cells were detected, which was then the crowning evidence for AFE. However, this was later debunked [39] (differentiation between maternal and fetal squamous cells is still difficult).

\section{FOUR SUBCLASSES OF ATYPICAL AFE}

The uterine hemorrhage-type of atypical AFE [16,26,27,

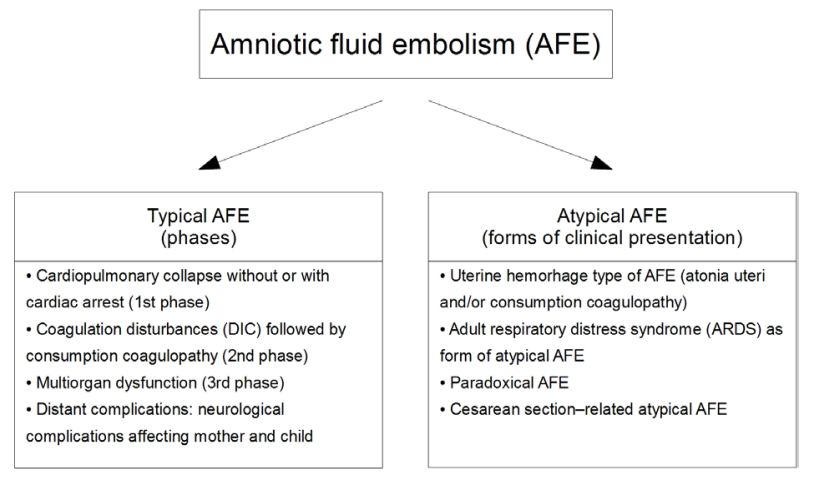

Figure 1. Amniotic fluid embolism-two clinical forms: typical and atypical presentation.

30-36,38]: This subclass was considered when the initial presentation of AFE was peripartal bleeding that developed without antecedent cardiopulmonary disturbances. Quite frequently it was massive uterine hemorrhage immediately followed by the delivery of the placenta. Uterine atony and coexisting consumption coagulopathy (DIC) induced by an embolic bolus of amniotic fluid could be seen as a cause of hemorrhage. Thus, subclinical consumption coagulopathy would show up rapidly with the moment of placental period of labor or cesarean section. In the past, the diagnosis was considered certain if circulating epithelial squames were found. However, the credibility of such evidence was discredited (failure to distinguish between fetal and maternal squames) [39]. The idea to search for meconium components and lanugo hairs in the circulating blood instead of epithelial squames seems justified [21].

ARDS-type of atypical AFE: ARDS (Acute Respiratory Distress Syndrome, previously called shock lung, sometimes referred to as non-cardiogenic pulmonary edema or adult respiratory distress syndrome) is known as a noninfectious inflammatory process of small bronchi accompanied by exudate to the lumen of the pulmonary alveoli; the originating hyaline membranes interfere with gas exchange. We found only four reports of ARDS as AFE-induced complications [23,24,36,38].

Paradoxical AFE: It is a rare type of obstetric complication. It may occur in a parturient with patent foramen ovale or atrial septal defect; the embolic fluid causes DIC together with intarcardiac thrombi, which may lead to cardiac arrest or sometimes to stroke [34,35]. Epithelial cells, recognized earlier as undisputed evidence of AFE, were found in intracardiac thrombi. Surgical removal of a thrombus and closure of a pathological foramen restored normal function of the heart; correction of DIC and subsequent consumption coagulopathy is another aspect of rescue management.

Cesarean section-related atypical AFE: The symptoms can appear preoperatively, intraoperatively or postoperatively (Table 2): 
Table 2. Presentation of amniotic fluid embolism (AFE) related to cesarean section delivery.

\begin{tabular}{|c|c|}
\hline Symptoms attributed to AFE & Authors \\
\hline \multicolumn{2}{|l|}{ Before cesarean section: } \\
\hline - fetal distress (late decelerations, meconium-staind amniotic fluid) & {$[19,26,30-35]$} \\
\hline \multicolumn{2}{|l|}{ - fetal bradycardia followed by mother's disseminated intravascular coagulation (DIC) } \\
\hline \multicolumn{2}{|l|}{ During cesarean section: } \\
\hline \multicolumn{2}{|l|}{ - ventricular tachycardia and hypotension } \\
\hline $\begin{array}{c}\text { - drop in blood pressure disproportional to intraoperative blood loss, cyanosis plus reduced } \mathrm{pO}_{2} \text { and increased } \mathrm{pCO}_{2} \\
\text { - excessive intraoperative bleeding, subperitoneal ecchymoses in the uterine region, intracardiac } \\
\text { thrombus in case of paradoxical AFE }\end{array}$ & {$[18,28,32-37]$} \\
\hline \multicolumn{2}{|l|}{ - obstetric shock, cardiac arrest and consumptive coagulopathy } \\
\hline After cesarean section: & \multirow{8}{*}{ [Personal Communication] } \\
\hline - uterine bleeding with non-clotting blood and with no clots & \\
\hline - liquid blood in the abdominal cavity (reoperation) & \\
\hline - liquid blood in postoperative wound (without clots) & \\
\hline - wound dressings soaked with blood & \\
\hline - laboratory findings: consumption coagulopathy & \\
\hline - cardiac arrest and consumption coagulopathy & \\
\hline - shock, respiratory distress and coma & \\
\hline
\end{tabular}

a/AFE is sometimes preceded by prodromal symptoms such as fetal bradycardia (late decelerations) and/or meconium-stained amniotic fluid (fetal distress) followed by mother's symptoms of AFE [17,24,28-33]. This is probably the earliest effect of amniotic fluid invasion into the utero-placental circulation (induction of local DIC and impaired oxygen supply to the fetus);

b/During cesarean section, the initial presentation of AFE involves impaired oxygenation with no anesthetic causes and a sudden decrease in blood pressure disproportional to the intraoperative blood loss [30,32]; profuse intraoperative hemorrhage with or without uterine atony has also been noted [26,30-33]; intraoperative AFE with cardiac arrest and severe coagulopathy has been also described [16,26];

c/The initial presentation of AFE after cesarean section can be severe coagulopathy with bleeding from all intravenous puncture sites, the vagina and abdominal incisions; the postoperative wound can contain clot-free liquid blood (27, 36, 38, 40, personal communication).

\section{A FEW REMARKS ON THE DIAG- NOSTIC CRITERIA OF AFE}

-In vivo diagnosis of AFE is made on the basis of clinical presentation (clinical criteria), whereas supportive laboratory investigations only complement the clinical diagnosis. Noncardiogenic and nonhemorrhagic obstetric shock is considered a pathognomic and initial sign of typical (classical) AFE.

-Typical AFE is characterized by three clinical phases (cardiopulmonary collapse, clotting disorders and hemorrhages, multiorgan disturbances), whereas the atypical one shows lack of cardiopulmonary collapse presen- tation-the first to appear is obstetric hemorrhage and/or pulmonary and renal dysfunction, that follow the initial symptom or appear as the only complications.

-Transesophageal echocardiography can provide arguments for the diagnosis following AFE (elucidates a few practical issues, e.g. whether there occurred pulmonary vasoconstriction or thrombus formation in pulmonary artery or in the heart $[15,16,40])$.

-Meconium components should be searched for in the maternal circulation, including zinc copro-porhyrin, sialyl Tn antigen, tryptase and complement factors as well as lanugo [41,42].

-For approximately 20 years circulating epithelial squames have been considered strong evidence of AFE. However, this turned out to be misleading-the squames could be either of fetal origin (fetal squames) or stratified squamous epithelial cells 'dragged' during transdermal vascular puncture [39].

-Post mortem diagnosis contributes greatly to the pathomorphological search-fetal squames, lanugo, mucus threads and fatty droplets can be all seen in pulmonary vessels; these components frequently form clusters coated with neutrophils and macrophages, and sometimes microthrombi can be found with the amniotic cells inside. A few authors have postulated that massive embolism with such a pathomorphological picture should be considered pathognomonic evidence of AFE [40].

\section{DIFFERENTIAL DIAGNOSIS}

Amniotic fluid embolism has to be discriminated from pulmonary embolism in the course of venous thromboembolic disease, aeroembolism (may occur after cesarean section) and fatty embolism (accompanies bone 
fractures). Advice to consider the possibility of cardiogenic and septic shock (sepsis) as well as aspiration syndrome (Mendelson's syndrome) seems justified [9]. Postpartum atony of the uterus due to other reasons than atypical AFE should also be considered in differential diagnosis. A warning made by Thomson and Budd in 1965 [43] is worthy to remember: “...let us be careful not to make ...the diagnosis of amniotic fluid embolism a wastebasket for all cases of unexplained death in labor”.

\section{FINAL REMARKS (CONCLUSIONS)}

(i) We found 447 cases of AFE described worldwide, including 70 cases of atypical AFE (15.7\%). (ii) Based on casuistic reports, we distinguished four subclasses of atypical AFE, which may have clinical implications. (iii) On one hand, it is not certain whether atypical AFE is properly diagnosed (under-or overestimation). However, on the other hand, it is known that the term atypical AFE has not been used in epidemiological reports. (4i) Our hypothesis concerning discrepancies in the incidence of AFE between Europe and North America seems justified and confirmed by our findings. However, appropriate prospective research is required as we failed to settle the hypothesis itself.

\section{REFERENCES}

[1] Clark, S.L., Hankins, G.D.V., Dudley, D.A. and Dildy, G.A. (1995) Amniotic fluid embolism: Analysis of the national registry. American Journal of Obstetrics \& Gynecology, 172, 1158-1169. http://dx.doi.org/10.1016/0002-9378(95)91474-9

[2] Meier, P.R. and Bowes, W.A. (1983) Amniotic fluid-like syndrome presenting in the second trimester of pregnancy. Obstetrics \& Gynecology, 61, 31S-34S.

[3] Steiner, P.E. and Lushbaugh, C.C. (1941) Maternal pulmonary embolism by amniotic fluid as a cause of obstetric shock and unexpected deaths in obstetrics. JAMA, 117, 1245-1254. http://dx.doi.org/10.1001/jama.1941.02820410023008

[4] Uszyński, M. (2011) Amniotic fluid embolism: Literature review and integrated concept of pathomechanism. Open Journal of Obstetrics \& Gynecology, 1, 178-183. http://dx.doi.org/10.4236/ojog.2011.14034

[5] Uszyński, M. and Uszyński, W. (2012) A new approach to the pathomechanism of amniotic fluid embolism: Unknown role of amniotic cells in the induction of disseminated intravascular coagulation. Asian Pacific Journal of A.P.J. Reproduction, 1, 326-329.

[6] Conde-Agudelo, A. and Romero, R. (2009) Amniotic fluid embolism: An evidence-based review. American Journal of Obstetrics \& Gynecology, 201, 445.e1-13.

[7] Knight, M., Berg, C., Brocklehurst, P., Kramer, M., Lewis, G., Oats, J., Roberts, ChI., Spong, C., Sullivan, E. and van Rosmalen, Z.J. (2012) Amniotic fluid embolism incidence, risk factors and outcomes: A review and recom- mendations. BMC Pregnancy Childbirth, 12, 10-17.

[8] Abenhaim, H.A., Azoulay, L., Kramer, M.S. and Leduc, L. (2008) Incidence and risk factors of amniotic fluid embolismus: A population-based study on 3 million births in the United States. American Journal of Obstetrics \& Gynecology, 199, 49.e1-49.e8.

[9] Troszyński, M., Chazan, B., Kowalska, B., Jaczyńska, R. and Filipp, E. (2003) Four main reasons of maternal deaths in Poland (in Polish). Ginekologia Polska, 74, 13061315.

[10] Kramer, M.S., Rouleau, J., Liu, S., Bartholomew, S. and Joseph, K.S. (2012) Maternal health study group of the Canadian perinatal surveillance system. Amniotic fluid embolism: Incidence risk factors, and impact on perinatal outcome. BJOG, 119, 874-879.

http://dx.doi.org/10.1111/j.1471-0528.2012.03323.x

[11] Albrechtsen, O.K. (1964) Haemorrhagic disorders following amniotic fluid embolism. Clinical Obstetrics and Gynecology, 72, 361-372.

http://dx.doi.org/10.1097/00003081-196406000-00009

[12] Thompson, A.J. and Greer, I.A. (2000) Non-haemorrhagic obstetric shock. Best Practice \& Research Clinical Obstetrics \& Gynaecology, 14, 19-41.

http://dx.doi.org/10.1053/beog.1999.0061

[13] Hankins, G.D.V., Synder. R.R., Clark, S.L., Schwarz, L., Patterson, W.R. and Butzin, C.A. (1993) Acute hemodynamic and respiratory effects of amniotic fluid embolism in the pregnant goat model. American Journal of Obstetrics \& Gynecology, 168, 1113-1130. http://dx.doi.org/10.1016/0002-9378(93)90355-M

[14] Clark, S.L. (1990) New concept of amniotic fluid embolism: A review. Obstetrical and Gynecological Survey, 45, 360-368. http://dx.doi.org/10.1097/00006254-199006000-00003

[15] Shechtman, M., Ziser, A., Markovits, R. and Rosenberg, B. (1999) Amniotic fluid embolism: Early findings of transesophageal echocardiography. Anesthesia \& Analgesia, 89, 1456-1458.

[16] Stanten, R.D., Iverson, I.G., Daugharty, T.M., Lovett, S.M., Terrt, C. and Blumenstock, E. (2003) Amniotic fluid embolism causing catastrophic pulmonary vasoconstriction: Diagnosis by echocardiogram and treatment by cardiopulmonary bypass. Obstetrics \& Gynecology, 102, 496-498. http://dx.doi.org/10.1016/S0029-7844(03)00161-3

[17] Porat, S., Leibowitz, D., Milwidsky, A.,Valsky, D.V., Yagel, S. and Anteby, E.Y. (2004) Transient intracardiac thrombi in amniotic fluid embolism. BJOG: The International Journal of Gynecology \& Obstetrics, 111, 506-510.

[18] Graeff, H., Hafter, R. and von Hugo, R. (1977) Molecular aspects of defibrination in case of amniotic fluid embolism. Journal of Thrombosis and Haemostasis, 38, 724726.

[19] Tuffnell, D.J. (2005) United Kingdom amniotic fluid embolism register. BJOG, 112, 1625-1629. http://dx.doi.org/10.1111/j.1471-0528.2005.00770.x

[20] Morgan, M. (1979) Amniotic fluid embolism. Anesthesia, 34, 20-32. http://dx.doi.org/10.1111/j.1365-2044.1979.tb04862.x 
[21] Bastien, J.L., Graves, J.R. and Bailey, S. (1998) Atypical presentation of amniotic fluid embolism. Anesthesia \& Analgesia, 87, 124-126.

[22] Davies, S. (1999) Amniotic fluid embolism and isolated disseminated intravascular coagulation. Canadian Journal of Anesthesia, 46, 456-459.

[23] Masson, R.G. (1992) Amniotic fluid embolism. Clinics in Chest Medicine, 13, 657-665.

[24] Huńka, I., Pożoga, J., Popielarz-Grygalewicz, J., Kotlarska, J. and Dąbrowski, M. (2003) Amniotic fluid embolism in 24-year-old female after caesarean section-A case report (in Polish). Kardiologia Polska, 59, 325-327.

[25] Awad, I.T. and Shorten, G.D. (2001) Amniotic fluid embolism and isolated coagulopathy: Atypical presentation of amniotic fluid embolism. European Journal of Anaesthesiology, 18, 410-413.

[26] Yang, J.I., Kim, H.S., Chang, K.H., Ryu, H.S. and Joo, H.J. (2006) Amniotic fluid embolism with isolated coagulopathy: A case report. The Journal of Reproductive Medicine, 51, 64-66.

[27] Porter, T.F., Clark, S.L., Dildy, G.A. and Hankins, G.D.V. (1996) Isolated disseminated intravascular coagulation and amniotic fluid embolism. American Journal of Obstetrics \& Gynecology, 174, 486.

[28] Barrows, J.J. (1982) A documented case of amniotic fluid embolism presenting as acute fetal distress. American Journal of Obstetrics \& Gynecology, 143, 599-600.

[29] Levy, R., Furman, B. and Hagay, Z.J. (2004) Fetal bradycardia and disseminated coagulopathy: Atypical presentation of amniotic fluid emboli. Acta Anaesthesiologica Scandinavica, 48, 1214-1215. http://dx.doi.org/10.1111/j.1399-6576.2004.00511.x

[30] Uszyński, M., Biłyk, B., Jesionowski, Z., Uszyński, W. and Koperski, M. (1984) A favourable result of heparin administration in two cases of clinically diagnosed amniotic fluid embolism (in Polish). Ginekologia Polska, 55, 625-630.

[31] Tramoni, F., Valentin, S., Robert, M.O., Sergeant, M.V., Branche, P., et al. (2004) Amniotic fluid embolism during caesarean section. The International Journal of $\mathrm{Ob}$ stetric Anesthesia, 13, 271-274. http://dx.doi.org/10.1016/j.ijoa.2004.03.002

[32] Uszyński, M. (1984) Heparin therapy in the primary phase of amniotic fluid embolism. Thrombosis and Haemostasis, 52, 362.

[33] Esposito, R.A., Grossi, E.A., Coppa, G., Gianola, G., Ferri, D.P., Angelides, E.M. and Andriakos, P. (1990) Successful treatment of shock caused by amniotic fluid em- bolism with cardiopulmonary bypass and pulmonary artery thromboembolectomy. American Journal of Obstetrics \& Gynecology, 163, 572-574. http://dx.doi.org/10.1016/0002-9378(90)91200-V

[34] Kumar, S., Wong, G., Maysky, M., Shulman, M., Olenchock, S., Falzon-Kirby, M. and Oo, T.H. (2010) Amniotic fluid embolism complicated by paradoxical embolism and disseminated intravascular coagulation. American Journal of Critical Care, 19, 379-382. http://dx.doi.org/10.4037/ajcc2009957

[35] Lee, P.H.U., Shulman, M.S., Vellayappan, U., Symes, J.F. and Olenchock Jr., S.A. (2010) Surgical treatment of an amniotic fluid embolism with cardiopulmonary collapse. The Annals of Thoracic Surgery, 90, 1694-1696. http://dx.doi.org/10.1016/j.athoracsur.2010.05.017

[36] McDougaall, R.J. and Duke, G.J. (1995) Amniotic fluid embolism syndrome: Case report and review. Anaesthesia and Intensive Care Journal, 23, 735-740.

[37] Johnson, T.R.B., Abbasi, I.A. and Urso, P.J. (1987) Fetal heart rate patterns associated with amniotic fluid embolism. American Journal of Perinatology, 4, 187-190.

[38] Fletcher, S.J. and Parr, M.J.A. (2000) Amniotic fluid embolism: A case report and review. Resuscitation, 43, 141146.

[39] Clark, S.L., Pavlowa, Z., Greenspoon, J., Horenstein, J. and Phelan, J.P. (1986) Squamous cells in the maternal pulmonary circulation. American Journal of Obstetrics \& Gynecology, 154, 104-106. http://dx.doi.org/10.1016/0002-9378(86)90402-3

[40] James, C.F., Feinglass, N.G., Menke, D.M., Grinton, S.F. and Papadimos, T.J. (2004) Massive aqmniotic fluid embolism: Diagnosis aided by emergency transesophageal echocardiography. International Journal of Obstetric Anesthesia, 13, 279-283.

[41] Kanayama, N., Yamazaki, T., Naruse, H., Sumimoto, K., Horiuchi, K. and Terao, T. (1992) Determining zinc coprophyrin in maternal plasma-A new method for diagnosing amniotic fluid embolism. Clinical Chemistry, 38, 526-529.

[42] Kobayashi, H., Ohi, H. and Terao, T. (1993) A simple, noninvasive, sensitive method for diagnosis of amniotic fluid embolism by monoclonal antibody TKH-2 that recognizes NeuAcalfa2-6Ga1NAc. American Journal of Obstetrics \& Gynecology, 168, 848-853. http://dx.doi.org/10.1016/S0002-9378(12)90832-7

[43] Thompson, B.W. and Budd, J.W. (1965) Erroneous diagnoses of amniotic fluid embolism. American Journal of Obstetrics \& Gynecology, 91, 606-620.

\author{
Abbreviations: \\ AFE-Amniotic Fluid Embolism, \\ ARDS-Acute Respiratory Distress Syndrome, \\ DIC-Disseminate Intravascular Coagulation, \\ TAT-Thrombin-Antithrombin Complex.
}

